\title{
The Status of Writer Illustrators (Autorstrator) in the Position of a Writer and Illustrator in Postmodern Illustration Books
}

\author{
Masoud Mojaveri Agah \\ $\mathrm{PhD}$ in Philosophy of Art, Department of Graphic Design, \\ Shahr-e-Qods Branch, Islamic Azad University, Tehran, Iran
}

\begin{abstract}
Postmodern illustrators are looking for differences. This distinction means attention to social state, gender, race, nationality, nature, geographical zone and etc. It should be noted that when postmodernism emerged in the fields of art, critics or addressees adjusted themselves with that and they took different interpretations for granted. The main goal of postmodern tendency could be "making clarification and opening doors to the facts created by ourselves". Most contemporary researchers and critics and all postmodern critics believe that any given artistic work has been created by a great number of artists so that the addressees can make different interpretations. In applied illustration art, which is in debt of late postmodern approaches, a type of illustrated products in the form of books entitled postmodern graphical novel should be a masterpiece. The complicated approach in creating single narrative frames, on the one hand, and the relationship between these frames, on the other, is the core points of discussions in the perspective of graphic novel or compiled illustration. One of the most significant features of producing a postmodern work for children can be the creator of that work i.e. the writer illustrator. In this line, the state of this writer-illustrator has been questioned.
\end{abstract}

Keywords: the illustrator a poet, a philosopher, a historian, narrator, designer or a semiotician.

\section{Intorduction}

\section{The Game of Language}

It is better to have a retrospect to answer this question when Lyotard brought up language games with denying meta narratives in postmodern condition. This hypothesis resulted in extension of local narratives in thoughts, philosophy and art. "When meta narratives are disregarded, we face a set of disharmonized language games, and the purpose of postmodern should be a fair treatment with them i.e. to allow them to be heard in their own language". (Malpas, 2003) local narratives claim to be universal so that they seek to express some limited and unique issues and thoughts.

This approach has spread out like other arts in illustration and the interaction of two languages of illustration and written in the form of book can be found today. The narrations which talk about ideas, preoccupations, and individuality of their creators themselves, and the writer-illustrators walk beyond the predetermined rules to show some new "language games". These games share the perspectives and individuality of the artist with others and they are affected by some elements such as society, geography, culture, nationality, religion, gender, ideology and etc. The way to breakout the rules and constitute new ones are different in illustrations. Lyotard has used "Philosophical investigations (1953) by Ludwig Witgenstein and introduced three rules for this term (language games): 1-The rules are not legitimate on their own, but they are contractual, implied or overt among the players. 2-If there are no rules, there is no game. In other words, a minor change in the rules can't change the nature of the game. If a "move' or chunk is not accepted or acted upon, they can't belong to the game which determine and identifies those rules. 3- The third assumption has been mentioned based on what went aforementioned; each chunk should be considered as a "move" in the game (Lyotard, 1983). On this line, it can be perceived in postmodern illustration complied books; the narration creator will offer new rules necessary for the condition. Therefore; the reader will face new environment and narrations in the method of the specific illustration which can be influenced by the application or the concepts meant by the creator. 
One of the best examples of postmodern complied illustration books can be "Willy's pictures" by Anthony Browne. A significant characteristic of this work is using the phenomenon of appropriation in the narration to turn it into an exclusive narration/game with the integration of Willy's narration. The narration, initially, starts with Willy's interest in pictures; "Willy is interested in pictures, he looks at them and he knows that each picture narrate a story". Willy is sitting behind his desk with a brush in his hand and smiling at the spectator. In the other frames, Willy shares his paintings with the readers. Each picture is a kind of interpretation by Willy or Browne through famous works of art, and these art pieces are used to narrate the story. At the bottom of each picture, there is a title in capital for the picture and Willy expresses his feelings or explains about the narration below each picture. In fact, Browne plays with the rules of classic paintings, for the favor of Willy, a chimp created and born in postmodern era and this chimp welcomes the roles suggested by the writer-illustrator. Willy, as the main character of this visual narration/game, narrates an adventure in each frame and he is a part of this narration/game. In the meantime, his "moves" work as the game rules. He is situated in some different eras in each frame and he paraphrases the concepts, the rules of the narration/game and his belies (picture 1). what is important for the reader in this step is difference and change; the difference between this picture and the original one, and the change/motion which has been created by the writer-illustrator necessarily. This is has made Browne's work unique and it is separated from other classic and modern works. If the reader is familiar with such works, he will make a communication between the original work and Browne's transparence and the reflections, created by the original work, can't be taken for granted. From the other side, changes and differences are revealed strongly in such woks, and the text, as a part of work, expresses the feelings, narrations and the chimp's perspectives encountering each picture. In this situation, as the reader commutes between the original work and Browne's, it can benefit differences and changes because what makes him refer to the classic and modern paintings is just he visual similarity of the picture. The addressee finds the new environment and space pleasant and in this way, he looks at classic and modern paintings and artists. Therefore; changes and differences or "moves" play an important role as the perspective or individual narration made by the writer-illustrator. If these "moves" are essential in such a postmodern compiled illustration work, the determined role of new rules and language games, as a person who has defined them based on their application, finds an important state. When we think about classic and modern art and painting, we pass Browne's ideas and at first we pay attention to Willy's narration. Willy is a familiar story and this name is associated with Browne. Assumingly, if we are not familiar with Willy's stories, the moment we look at the pictures, we are immediately affected by what Browne has created for us. For example, the chimp, his age and size, his clothes, his relationship with other elements and characters, changes of the pictures and the like are the features which we are absorbed to. Browne, as the author of this compiled illustration book, has taken classic and modern works of art from museum walls to the pages of his book, as a "medium", a new bed to exhibit art in the modern era. He has cleverly defined a new frame for each picture and placed them inside the pages of his painting book in order to emphasize his presence and perspective. He has used the phenomenon of ownership in postmodern art to emphasize the creation of any artistic work created by a number of artists and to facilitate different interpretations by the addressees (Barrett, 2012). These interpretations depend on the game rules created by Browne himself.

Indeed, the role of the author can't be denied and rely on the infinity of meaning, the writer-illustrator is the person to determine the game rules to open up the ways for different interpretations. Foucault believes that the writer facilitates cancerous and dangerous spread of reasons in a world in which not only resources and wealth, but also words and reasons are economized. The writer is the main source to economize multi-meanings (...........), he is a practical reason that we limit it, eliminate it and select it by culture. In sum, we block the circulation and changes, free composition and analysis, and reconstruction of free dreams(Foucault, 2013). In general, in discourse, postmodern complied illustration books, we face two disciplines of sign language and picture and each of them provide us with different data, and they also affect out overall interpretation of the narration. The constitutor of these game/discourse rules is one person who manages all the discourse discipline pragmatically. In this situation, written sign discipline is moving ahead chronologically, but the iconic discipline is location based. In the book "The Red Tree" by Shaun Tan, this pragmatic interaction and agreement can be vividly observed. Initially, we encounter a picture and we read the elements based on the locations in the framework, the proportion of the frame and the size of the book are definable and they influence the relationship between the elements in the frame, the little girl, the red leaf, airplanes, human-like creatures and etc (picture 2). The text, in this part, is placed in the frame as a part of the picture. Our reading and interpretation depends on our concentration and focus on the location based picture. In this line, chronological signs are attended as a part of picture and during the reading phase, and the interaction with these visual signs, based on location relationships in the frame, are altogether redefined. This situation is to disrupt the predetermined rules for the favor of language game or localized narration which aim to be heard or seen in their own language. Their own language means the language of the work's creator, and the addressee is affected by this 
subject or narration. In the next frame, the boxes are in smaller sizes rhythmically. What makes us follow these pictures can be their accidental and rhythmic setting, and something is occurring in each box and it makes us move on to the next one. The texts which go along with the pictures shouldn't be disregarded because a neat combination of the relationship between the text and picture can lead us to some concepts such as expectance, futility, repetition, and the position of the main character who represents human being. We are helped out and guided with such concepts and this means the interaction between a text and picture (picture 3). Behind such a pragmatic interaction and agreement, there is a writerillustrator who has the main role and organizes the visual and written elements, the man character (the little girl), the size of frames, proportions, sentences and words in the text and the like.

\section{Game of signified}

Barthes brings up a text with multi-meaning; a text which can be present or not in a work. The work is in hand, but the text in the language. In this respect, the role of the writer is faded away and Barthes mentions the following as the main features: non-consumable, multicity, paradox, symbolic, transitory, incalculable and unpredictable, as well as irreversible. He believes that signs can help to approach the text and experience it. A work consists of a signification. Two significations can be considered for such a signified; it is either vividly revealed so that it belongs to literal science i.e. terminology or it is hidden so that it should be sought out, hence; moving to the arena of interpretations. In short, apiece works as a general sign so that it reflects the sign civilization. A text moves signified backwards continuously, a text is almost motionless, its arena is a signifier arena; a signifier shouldn't be regarded as the first part of meaning or a materialistic transition, but it should be considered as a consequence. On the same line, the infinity of a signifier doesn't refer to an unmentionable assumption with an unnamed signified, but it refers to a type of game (Barthes, 2013). Based on this hypothesis, the readers are free to open up the reasonability process of a text regardless of signified and to carry it as far as they would like. Such an approach makes the addressees forget the author. If the author relies on the game of signifiers and postpone the signified in the work, the work shouldn't be treated idea-centered. In this situation, personal meanings and concepts of the writer-illustrator, whose ideas have been the bases of this illustration work, are lost altogether, and the language games and local narrations which have been seen or heard in one way or another lose their whole meanings. Indeed, such characteristics- infinity of signifiers- should be found in the text in order to make the addressee have an interaction with that and to turn to the writer of this text. For better clarification, we can consider "The Three Pigs" by David Wiesner. What makes this work stands out can be the anarchy found in this familiar type of narration; the escape of these pigs from their destiny and their usual narration. In this situation, the main idea of the writer-illustrator moves ahead of addressee's critical reading and the addressee goes along with the creator (picture 4). Wiesner also shows a type of forming the meaning by a number of people in the postmodern art through some narrations in visual language. In this process, the writer-illustrator determines the game rules by the formation of such meanings, the starting point, the middle, the climax and the ending of the story, the characters, the method to represent the pictures, the size of frames and boxes, the views, plans, appropriations and etc. and each of them affect the desired meaning and concepts of the work. For example, the environment in which the pigs are put in their story and other stories is a colorless area/white, infinite and full of pictures from different stories which are placed harmonically next to each other. Taking a look at this environment is the idea and thought that the work creator has visualized and the addressee views it with such specifications and reads it.

At this point, we don't want to deal with Barthes' reasonability, but the iconic and symbolic signs are placed in a discourse based setting for a common purpose. This shared aim prevent explosion and spread of meaning considered by Barthes because postmodern works can live in a game of signified and in line of concepts, interpretation and commentaries, not in the game of signifiers. A compiled illustration work is a composition of approaches, discourses, genres, and different viewpoints dependant on the creator's ideas and thoughts. In fact, this is the postmodern language game which speaks in the language of its creator- language of pictures.

\section{Language of pictures}

Every picture uses a method of explanation and a system of discourse. The moment something is placed in a box or frame, discourse is imposed to it and attention is made to express that this picture defines something from the creator's view. Therefore, a picture shows presence and what could be absent emerges the way that the speaker would like. This presence carries some traces of the presenter. The visual speaker is a medium between the viewer and the world that is hidden from the viewer and/or it is present is a different way(Shairi, 1393). In this situation, a trace of the presenter means personal methods used by the presenter or writer-illustrator in order to organize visual discourse or local narrations. Some methods 
which distinguish him/her from others, since any artist or writer-illustrator has been trained and grown up us a special society or culture, his/her work can reflect different thoughts, societies and cultures which form their individuality.

In the first frame of "The Red Tree", after conveyance, we can see the main character on a stool in a plain, having an amplifier like a cone with closed eyes and sad face in the center of the box. Shaun Tan has designed a human character ( a little girl) which is made by two triangles and for him, being a human is more important not the gender or other qualities. This little girl doesn't belong to any time or location so that the viewer is not led to any culture or geographical zone. She is the representative of humanity. She is redefined according to the location she is put in with the red leaf carrying along. In this frame, the letters fall out of the amplifier to the outer side of the frame, and this situation represents chaos and downfall of written signs along with the changes in the application of the amplifier as a messenger to indicate the inability of this little girl to shout her own internal thoughts. Shaun Tan has used light contrasts in her hair and clothes to show her chaotic and anxious internal and these features come with her inability to show her inner thoughts, feelings and making relationships. However, this characteristic is the result of her presence is an environment which is shown by expressionist lines of the plain, tough contrasts of cold and warm lights, and the girl has a role which is set in line with her own feelings and spirits. Selecting a vertical frame in line with the location of the character, the break of this line in the upper one-fourth of the frame and background indicate a preventive force to express feelings. The cold color used in this section might show a sensitive and fragile part of the girl which doesn't allow her to talk. That is why the words fall on the ground and out of the frame (Picture 5). In another picture of the book, the girl is at the beginning of a road with her back to the viewer carrying a big dice in her hand. At the other end of this road, there is giant creature having a sand clock. The relationship between this creature and the long road and this dice-carrying girl can be defined based on the location signs which finally can lead to a local narration taken from a creative thought (Picture 6). The most import event happening to the viewer is the pause which is made due to some unexpected things in the pictures. This pause brings around some many questions that lead the addressee focus and contemplate on the work. The more the spectator concentrates and the more he spends time on the inter-relationships of the signs, the better he can read in the narration. In this picture, the building with their shadows over the road or the girl's path can be of more attention due to their vertical features. The giant creature is composed of whatever found on the road, a road which highlights the girl's determination to destiny (dice), her suspicion and dependence due to some light and dark parts on the road. The presence of a vane and the wind which agrees with the giant, a semi-cloudy sky in the background of the red leaf increase the doubts. The signs placed in the reticular frame of the main picture are considerable; some elements such as a spider, the sun, card game elements, a sand clock, an owl, a bow, a compass and etc. These signs can be defined and interpreted based on the technique and method or representation, placement, size, relationship with the surrounding environment, thought-philosophy ideas of the creator and the reader. When this pause and question are made, the narration happens through this magnificent picture and the reader tries to find out the relationships between the elements and read the pictures. A narration which is triggered initially from the personal thoughts of the writer-illustrator and the reader continues that through reading and understanding the place of the picture.

Writer-illustrators use some methods to define local narrations better. In some picture, we might come up with a set of relationships and elements taken from different situations such as the final picture of the Three Pigs. In this picture, three pigs, a ct and a dragon are having a soup together on a table. In the background, in the window frame, the wolf who made them escape is sitting in a smaller size. Although the dragon has occupied more space than the other characters, the cutting and his part of body out of the frame has made a balance among these characters. In addition, a balance of the environment has been made through using cold and silent colors in contrast to the warm colors of these pigs, the cat and the golden flower on the table. Even the grey pig is as important as the other characters in this frame. Each character points out at this pig in one way; the dragon with his head, the pig on the right and the cat with their eyes, and the pig on the dragon's lap with his feet. The triangular forms on the dragon's body take our eyes to the window, the wolf and the written signs. Wiesner has intelligently designed the pictures and environment in that none of these characters has priority over the others; a set of different situations which is taken from one position, a local narration and a different environment. Finally, a new local narration is made out of which the reader tries to make an interpretation based on the main idea(picture 7).

Sometimes, in contrast to what went before, there is a dominating element in pictures and other signs just refer to it. In one frame from The Red Tree, the picture of a semi-cloudy sky is reflected on a closed window, and a flying wonderful car is in the sky. When this flying car is placed in the window frame, it means there is a visual emphasis. The colors in this frame talk; the tangerine color of the clouds against the blue sky, and also the placement of the colors can take our attention to the flying car. On the other hand, the girl's imploring looks and the placement of the red leaf increase this emphasis (Picture 8). In this picture, all the elements and signs toward the flying and wonderful car have a narration. Each of these elements 
and signs carry a meaning and they organize other signs in the frame of the picture and make a relationship with them and try to have new and different meanings, concepts and local narrations.

The number of local narrations formed in compiled illustration works depend on the elements in the framework (people, animals, things) and their relationships. Sometimes, two elements and sometime more elements can lead the organizational relationships between symbolic signs (words), and in some frames, no sign has priority over the others. The writer-illustrator uses any sign or approach to express his/her own local narration in order to share his/her idea, view or individuality. Sometimes in one book, the frames are different based on their structure, technique, subject, characters and such elements and the reader is always surprised. At this point, what we know as a narration finds a new definition. This one relies on the writer-illustrator's main idea and symbolic and iconic signs. In this regard, a new language game is formed according to these interpretations and commentaries out of the formed relationship among them.

\section{Result}

Compiled illustration is the result of postmodern approaches to art and philosophy, an era which is the indicator of profound changes in perception and social behavior. Instead of making attempts to interpret some facts with some specific parameters, postmodern artists reflect a complicated world (Goldstone, 2008). This world heavily depends on the relationships of the signs so that they are definable. Writer-illustrators are well-familiar with different art periods, and they are capable designers who are well-matched with their own thoughts and they can clearly visualize their ideas. They know stylistic contracts and technical approaches so that they change them or break them whenever necessary. Their priority is expressing their own views and transferring a message. Despite all differences and variations found, the meanings of their works arise from where this work is composed. A writer-illustrator, knowing this subject uses these signs courageously in a visual relationship. These signs can have a local narration inside. This writer-illustrator wants to make the addressee understand his/her concepts through such local narrations or individual thoughts. In these narrations, the addressee follows an idea which is brought up by the writer-illustrator and continues it in a bed of interpretations and commentaries. The writer-illustrator invites the reader to look at the world with its wonderful pictures differently, and he is freed to take his other steps. In this respect, the writer-illustrator shares individuality with the addressee which is taken from a set of approaches, ideas, and thoughts learned in the passage of time and society and these have granted meaning to his identity.

\section{References}

[1] Barrett, Terry. (2012), Criticizing art: Understanding the contemporary, Translated by Kamran Ghabra-ee, Tehran: Nika.

[2] Barthes, Roland, (2013), From Work to Text, Translated by Safiye Rouhi, Tehran: Markaz.

[3] Foucault, Michel. (2013), What is an author?, Translated by Afshin Jahan dideh, Tehran: Markaz.

[4] Goldstone, Bette. (2008). "The Paradox of Space in Postmodern Picturebooks". Postmodern Picturebooks, Play, Parody, and Self-Referentiality. Routledge, Taylor \& Francis. pp117-129.

[5] Lyotard, Jean-Fran. (1983), The Postmodern Condition: A Report on Knowledge, Translated by Hossein Ali Nowzari, Tehran: Gaam-e-no.

[6] Malpas, Simon.(2003), Jean-Francois Lyotard, Translated by Ghamar-eddin Badir dast, Tehran: Ney.

[7] Shairi, Hamidreza. (2014),(Tahlil e Neshane ma'na shanakhti ye tasvir) Semiotic analysis of the picture, Tehran: Elm.

CHILDREN'S LITERATURE CITED

[8] Browne, Anthony. (2000). "Willy's Pictures". CandleWickPress: Cambridge, Massachusetts.

[9] Tan, Shaun. (2001). The Red Tree. Lothian Children Books.

[10] Tan, Shaun. (2008).(Derakht e Ghermez) The Red Tree,Translated by Lida Kavousi, Tehtan: Ney.

[11] Wiesner, David. (2001). The Three Pigs. New York: Clarion Books. 


\section{Pictures}

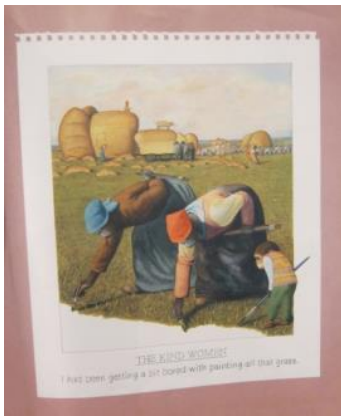

pic 1 (willy`s pictures, Anthony Brown)

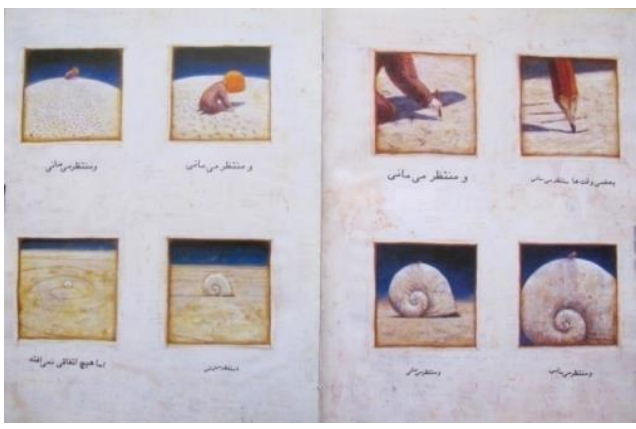

pic 2(The Red Tree, Shaun Tan)

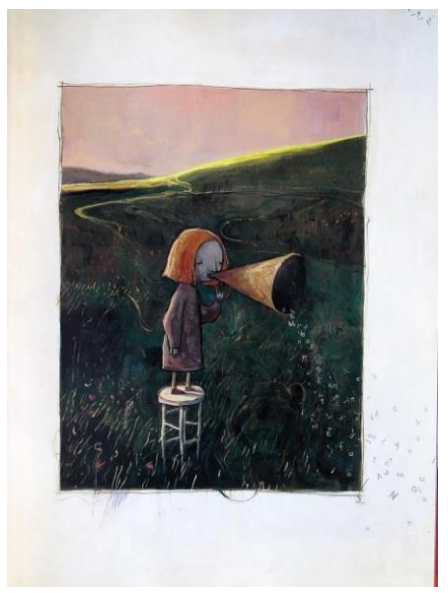

pic 5(The Red Tree, Shaun Tan)

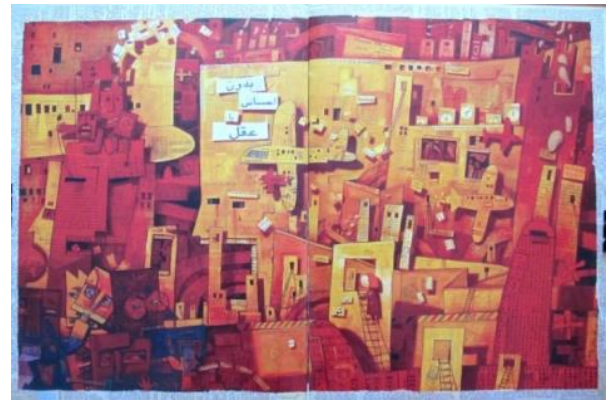

pic 2(The Red Tree, Shaun Tan)

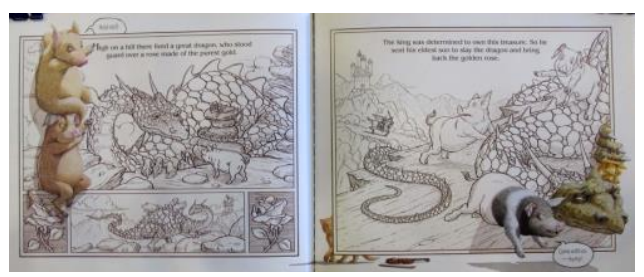

pic4(The Three Pigs)

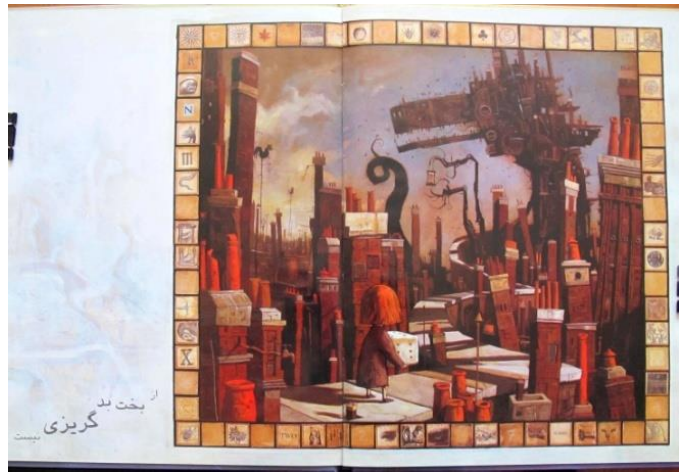

pic6(The Red Tree, Shaun Tan) 


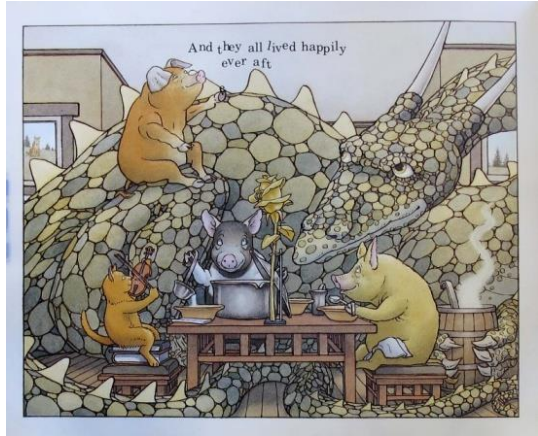

pic7(The Three Pigs)

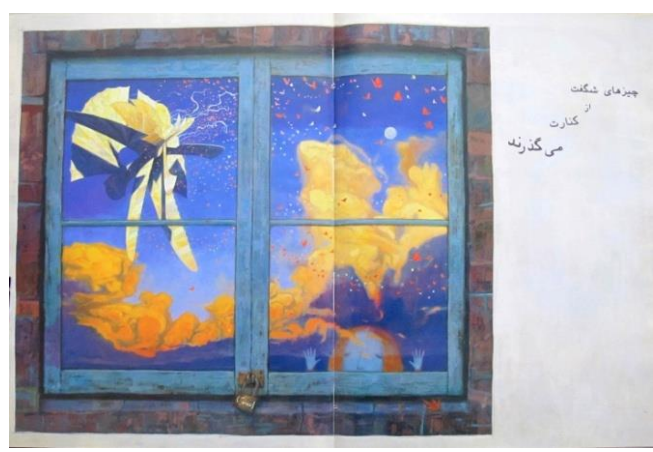

pic8(The Red Tree, Shaun Tan) 